\title{
Development and Validation of SVPT Device for Assessing Pinch Grip Strength among Neurological Patients
}

\author{
Mehta Krupa $^{1}$, Mair Kalpana ${ }^{2}$, Mair Sushrut ${ }^{3}$, Sorani Dinesh ${ }^{4}$, Rathod Sheshna ${ }^{5}$ \\ ${ }^{1}$ Consultant Physiotherapist at PDU Hospital, Rajkot, Gujarat, India. \\ ${ }^{2}$ Physiotherapist at Orthocare Orthopedic Clinic, Pune, India. \\ ${ }^{3}$ Technology Consultant, Pune, India. \\ ${ }^{4} \mathrm{I} / \mathrm{C}$ Principal, Government Physiotherapy College, Rameshwernagar, Jamnagar, Gujarat, India. \\ ${ }^{5}$ Tutor/Physiotherapist, Government Physiotherapy College, Rameshwernagar, Jamnagar, Gujarat, India.
}

Corresponding Author: Mehta Krupa

\begin{abstract}
Aim: The purpose of this study was to develop an instrument-Smart Virtual Physical Therapist (SVPT) that assess the pinch grip strength and its measurement was recorded on a Smartphone application, and to validate Smart Virtual Physical Therapist device with standard pinchometer device.

Method: Observational study was carried out on 40 patients having neurological condition and grip affection of 20-70 years of age. Measurement of pinch grip strength was done with SVPT device and pinchometer between pulp of thumb and pulp of index finger, middle finger, ring finger and little finger. The measurement was recorded in kilogram. Measurements were done once with right hand and then with left hand.

Results: Mean values for pinch grip by SVPT device for index, middle, ring and little finger of right hand were $1.92 \mathrm{~kg}, 1.74 \mathrm{~kg}, 1.40 \mathrm{~kg}, 1.11 \mathrm{~kg}$ and left hand were $1.84 \mathrm{~kg}, 1.71 \mathrm{~kg}, 1.43 \mathrm{~kg}, 1.04 \mathrm{~kg}$ respectively. In addition to it mean values by pinchometer for index, middle, ring and little finger of right hand were $3.02 \mathrm{~kg}, 2.87 \mathrm{~kg}, 2.17 \mathrm{~kg}, 1.61 \mathrm{~kg}$ and left hand were $2.84 \mathrm{~kg}, 2.94 \mathrm{~kg}, 2.28 \mathrm{~kg}, 1.62 \mathrm{~kg}$ respectively. $\mathrm{K}$ value for index, middle, ring and little finger of right and left hand was 0.2 . There were $25 \%$ of people who were unable to do pinch grip using pinchometer.

Conclusion: Smart Virtual Physical Therapist device can't be replaceable with the standard baseline pinchometer to assess the grip strength. But it is a valid tool to measure pinch grip strength in neurological patients due to greater height of pressure sensor of SVPT device for pad to pad grip.
\end{abstract}

Key Words: Hand, Instrumentation, Pinch strength

\section{INTRODUCTION}

The human hand is capable of performing grasping objects and manual dexterity. Functionally thumb and index finger are of more importance because of its musculature, strength, and interaction with other digits. The hand is very important for various types of grips necessary in activities of daily living. ${ }^{[1]}$

The grip is defined as a 'forceful act resulting in flexion at all the joints of the fingers along with thumb when used as a stabilizer to the object being held between the finger and the palm.' Grip strength is referred to as a reliable and valid objective parameter to evaluate the functional integrity of the hand as part of the musculoskeletal system. ${ }^{[2]}$ Grips are classified into two i.e. power grip and precision grip. Power grip includes cylindrical grip, spherical grip, hook grip, and fist grasp. ${ }^{[1]}$ Precision grip includes pulp 
to pulp pinch grip, tip to tip grip, pulp to side prehension, and three fingered pinch. Precision grip is used for activities that require accuracy. The estimated use of pulp to pulp pinch is $20 \%$ for activities of daily living. ${ }^{[3]}$

It is prominently accepted that grip and pinch strength measurements provide an objective index of the functional integrity of the upper extremity. ${ }^{[4]}$ Pinchometer is used to quantify the finger pinch strength. ${ }^{[5]}$

Recent studies have attempted to provide a definitive picture of the difference between dominant and non-dominant hand strength. Crosby et al investigated normative values of handgrip, pulp and key pinch and claimed that the population as a whole demonstrated significant differences between the dominant and non-dominant hands. ${ }^{[6]}$ In their study, hand grip and pulp pinch strengths were 6\% and 5\% higher for the dominant hand respectively.

Additionally, there are other studies which have reported influence of several factors on grip strength. Nurgul et al. ${ }^{[1]}$ reported that the dominant hand is stronger in right-handed individuals but no such difference was observed in individuals with left hand dominance. Kuzala et al. ${ }^{[7]}$ did a study to determine the effect of various elbow positions on grip strength and concluded that grip strength to be highest in elbow extension and lowest in full flexion.

Though the reference values are available from western populations, it would not be appropriate for use in an Indian setting, due to variations in genetic, environmental and nutritional factors which influence grip and pinch strength. ${ }^{[8,9]}$

Very few studies are available on Indian population that have given normative values for grip, tip, palmar and key pinch strength in an attempt to explore the association of grip strength with specific factors, namely age, relevant anthropometric factors, level of physical activity and profession. ${ }^{[10-12]}$

Evaluation of these grips and pinches is important in determining the effect of different treatment strategies and surgical procedures. $^{[1]}$ It also assesses patients' initial limitations and provides a baseline for re-assessment of patients' progress. Normative data are required to interpret, set realistic treatment goals and assess ability to return to employment. ${ }^{[9]}$

Dinesh Sorani et al. conducted a study to estimate the reference values for cylindrical grip strength in Gujarati population and to estimate the reference values for pinch grip strength in Gujarati population. They found that grip strength is higher in males compared to females. Hand dominance also affects grip strength. ${ }^{[12]}$

Mathiowetz et al., did a study to evaluate Grip and Pinch Strength: Normative Data for Adults and it was concluded that the highest grip strength scores occurred in the 25 to 39 age groups. A high correlation was seen between grip strength and age, but a low to moderate correlation between pinch strength and age. ${ }^{\text {9] }}$

César Fernández-de-las-Peñas et al., did a study to investigate differences in fine motor control ability and pinch grip force between patients with unilateral CTS and healthy controls. It revealed that patients with unilateral CTS exhibit bilateral deficits in fine motor control ability and pinch grip force in patients with unilateral moderate CTS when compared to controls. ${ }^{[13]}$

The standard baseline pinchometer is a valid tool to measure pinch strength in normal individuals but it has some limitations while measuring pinch strength in neurological patients because in them they are not able to do pad to pad contact as height of pinchometer is less. Whereas, in SVPT device height of pressure sensor which measures pinch strength is more so it becomes easy for the neurological patients to do pad to pad contact. ${ }^{[14]}$

So, the purpose of the present study is to develop SVPT device that assess the pinch grip strength in neurological patients and its measurement will be recorded with a wireless device on a Smartphone application. 


\section{MATERIALS AND METHODS}

Study design: Observational study

In the present study 40 patients having neurological condition and grip affection with age group of 20-70 years from Govt. Physiotherapy College OPD, Jamnagar, India were selected by simple convenient sampling. All subjects were informed about the purpose of the study and signed informed consent was taken from the patients. The demographic data like age, height, weight and hand dominancy was recorded for each subject.

Inclusion criteria: Both male and female subjects of 20 to 70 years, who were able to understand the technique and willing to participate in the study were taken. Neurological conditions that were included in the study were stroke (21 patients), Guillian Barre Syndrome (2 patients), partial spinal cord injury having paraplegia (3 patients), patients having compression neuropathy of median nerve. (5patients), cervical myelopathy (1 patients) and cervical radiculopathy ( 8 patients). Patients were assessed clinically using pinchometer. From it patients having poor pinch grip or those who were unable to do pad to pad grip using pinchometer were included in the study. The subjects with history of upper limb fractures, wrist drop, claw hand and erbs palsy were excluded.

Familiarization was done to the subjects by demonstrating the technique using Smart Virtual Physical Therapist (SVPT) device as well as pinchometer.

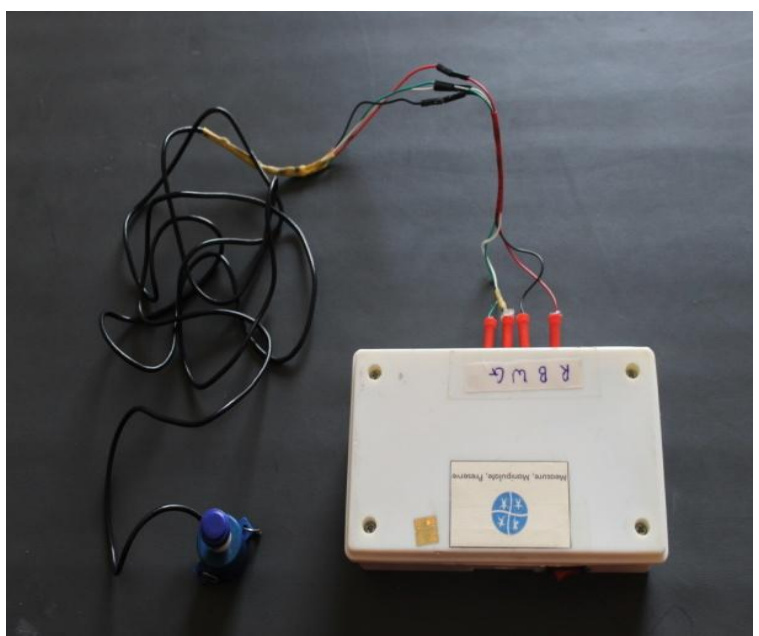

Image 1: SVPT Device

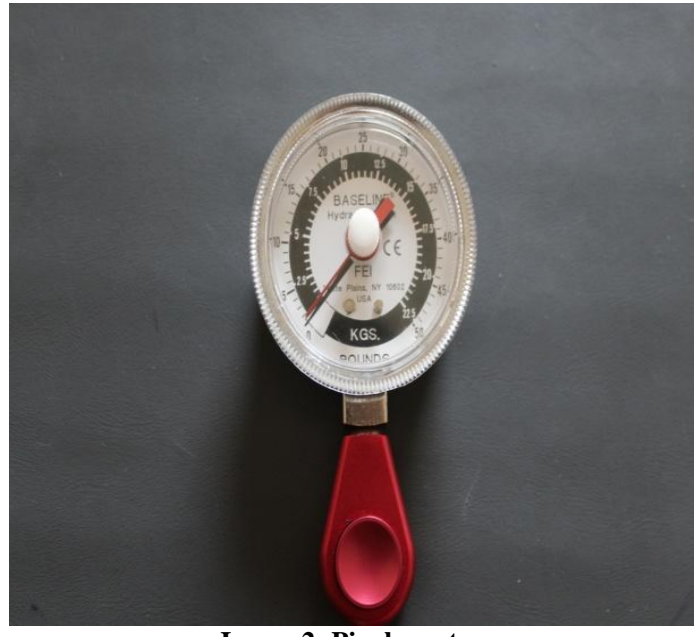

Image 2: Pinchometer

Materials and apparatus used:

- SVPT Device (as seen in image 1)

- Pinchometer (BASELINE®; 12-0226) (as seen in image 2)

- Goniometer

- Case record form

- Pen

- Paper

DESCRIPTION OF SVPT DEVICESVPT device consists of base unit, sensors and the mobile application. The application is connected to the base unit and sensor through wireless connectivity which provides visual biofeedback to the patients and the therapist about the activity. Apart from pinch grip analysis, SVPT device is capable of accommodating various other sensors so that it can manage a variety of physical therapy regimen.

\section{PROCEDURE}

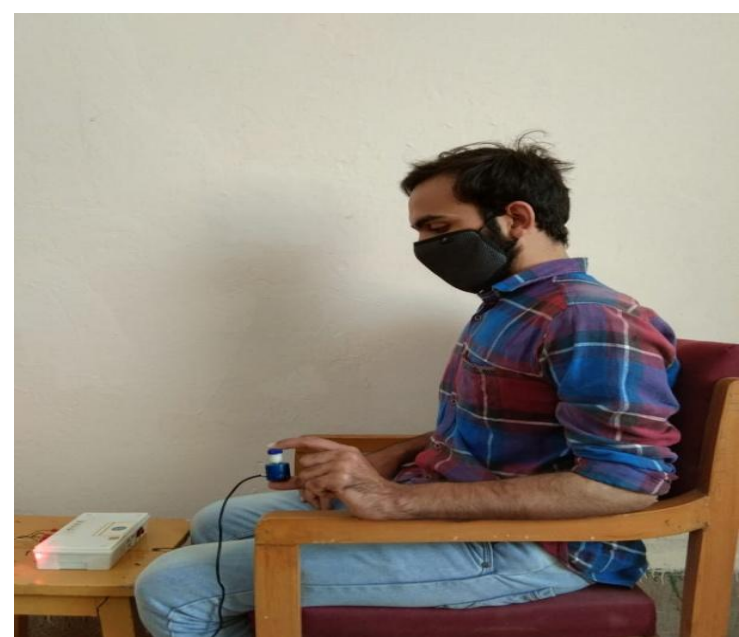

Image 3: Measurement of pinch grip using SVPT device 
Mehta Krupa et.al. Development and validation of SVPT device for assessing pinch grip strength among neurological patients.

Ethical clearance was obtained from ethical committee of M P Shah medical college, Jamnagar.

The subject was in sitting position on a chair with arm rest with 0 degree shoulder flexion, shoulder adducted and neutral rotation with elbow 90 degree flexed, forearm pronated and wrist in 20 degree of extension. Subject was asked to hold SVPT device between pulp of thumb and pulp of index finger, middle finger, ring finger and little finger and generate maximum force. Its measurement was recorded on a Smartphone application in kilogram. Three recordings were taken with sufficient rest period of 30 seconds between them. Best of three was used for final analysis. Measurements were done alternately on both hands (as seen in image $3)$.

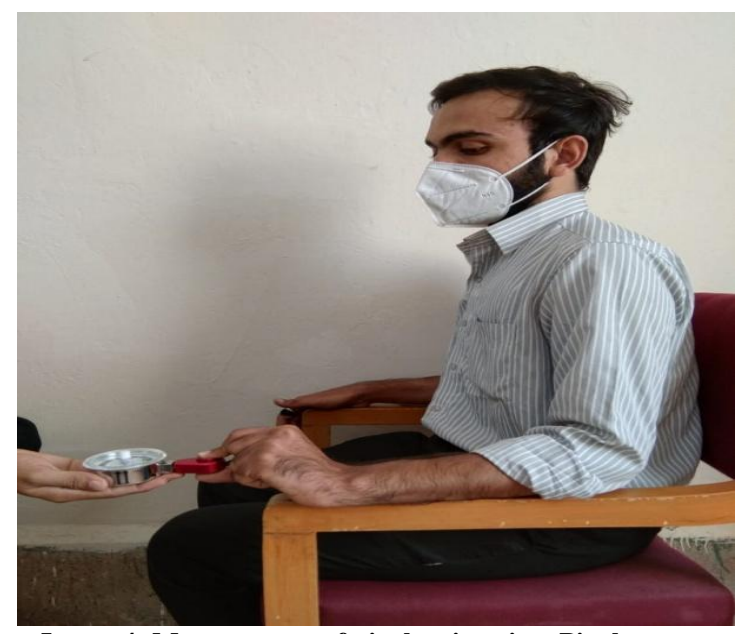

Image 4: Measurement of pinch grip using Pinchometer
The same procedure was followed for pinchometer and three recordings were taken with sufficient rest period of 30 seconds between them (as seen in image 4).

\section{STATISTICAL ANALYSIS}

Data was entered and analyzed in SPSS version 20. Mean and Standard Deviation (SD) were calculated as a measure of central tendency and measure of dispersion respectively. Along with it kappa statistics was calculated as a measure of agreement between SVPT device and Pinchometer.

\section{RESULTS}

Table 1: Demographic characteristics of all subjects

\begin{tabular}{|l|l|l|l|l|l|}
\hline \multicolumn{2}{|l|}{ Gender } & Age(yrs) & $\begin{array}{l}\text { Height } \\
\text { (meters) }\end{array}$ & $\begin{array}{l}\text { Weight } \\
(\mathbf{k g})\end{array}$ & $\begin{array}{l}\text { Body Mass } \\
\text { Index }\left(\mathbf{k g} / \mathbf{m}^{2}\right)\end{array}$ \\
\hline Male & 19 & 47.77 & 1.64 & 66.9 & 24.71 \\
Female & 21 & $(13.36)$ & $(0.10)$ & $(12.92)$ & $(4.87)$ \\
\hline
\end{tabular}

All data are expressed as Mean (SD), $N=$ number of subjects

Table 2: Mean Values and Standard deviation of SVPT Device and Pinchometer

\begin{tabular}{|l|l|l|l|}
\hline \multirow{2}{*}{$\begin{array}{l}\text { RIGHT } \\
\text { HAND }\end{array}$} & INDEX FINGER & $\begin{array}{l}\text { SVPT } \\
\text { Device(kg) }\end{array}$ & $\begin{array}{l}\text { Pinchometer } \\
\text { (kg) }\end{array}$ \\
\cline { 2 - 4 } & MIDDLE FINGER & $1.92 \pm 0.74 \pm 0.74$ & $3.02 \pm 0.96$ \\
\cline { 2 - 4 } & RING FINGER & $1.40 \pm 0.64$ & $2.17 \pm 0.85$ \\
\cline { 2 - 4 } & LITTLE FINGER & $1.11 \pm 0.54$ & $1.61 \pm 0.61$ \\
\hline \multirow{3}{*}{ HEFT } & INDEX FINGER & $1.84 \pm 0.82$ & $2.84 \pm 0.98$ \\
\cline { 2 - 4 } & MIDDLE FINGER & $1.71 \pm 0.82$ & $2.94 \pm 1.23$ \\
\cline { 2 - 4 } & RING FINGER & $1.43 \pm 0.64$ & $2.28 \pm 0.76$ \\
\cline { 2 - 4 } & LITTLE FINGER & $1.04 \pm 0.43$ & $1.62 \pm 0.47$ \\
\hline
\end{tabular}

All data are expressed as Mean (SD)

Table 3: Inter-rater agreement between SVPT device and Pinchometer

\begin{tabular}{|l|l|l|l|}
\hline & Kappa & 95\% CI & Strength of agreement \\
\hline Index finger & 0.23 & $0.14-0.32$ & Poor \\
\hline $\begin{array}{l}\text { Middle } \\
\text { finger }\end{array}$ & 0.23 & $0.14-0.32$ & Poor \\
\hline Ring finger & 0.23 & $0.12-0.33$ & Poor \\
\hline Little finger & 0.26 & $0.15-0.38$ & Poor \\
\hline
\end{tabular}

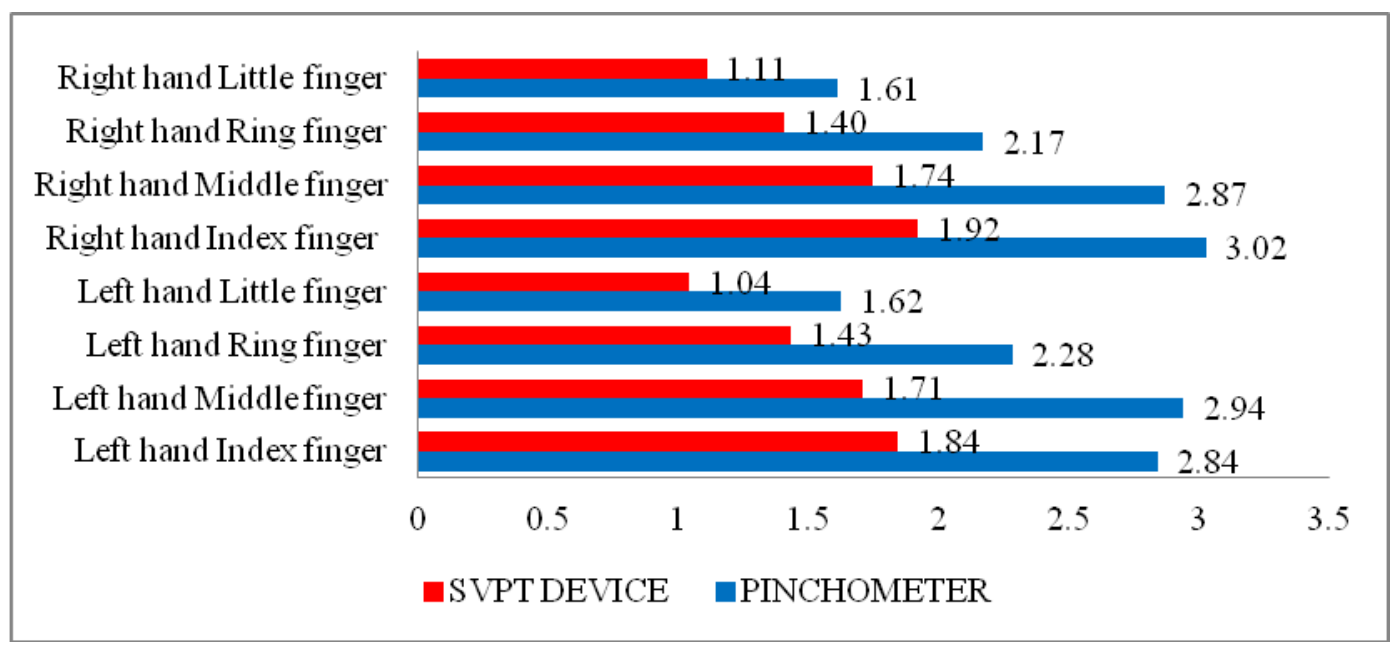

Graph 1: Comparison of Mean Values of SVPT Device and Pinchometer 
Mehta Krupa et.al. Development and validation of SVPT device for assessing pinch grip strength among neurological patients.

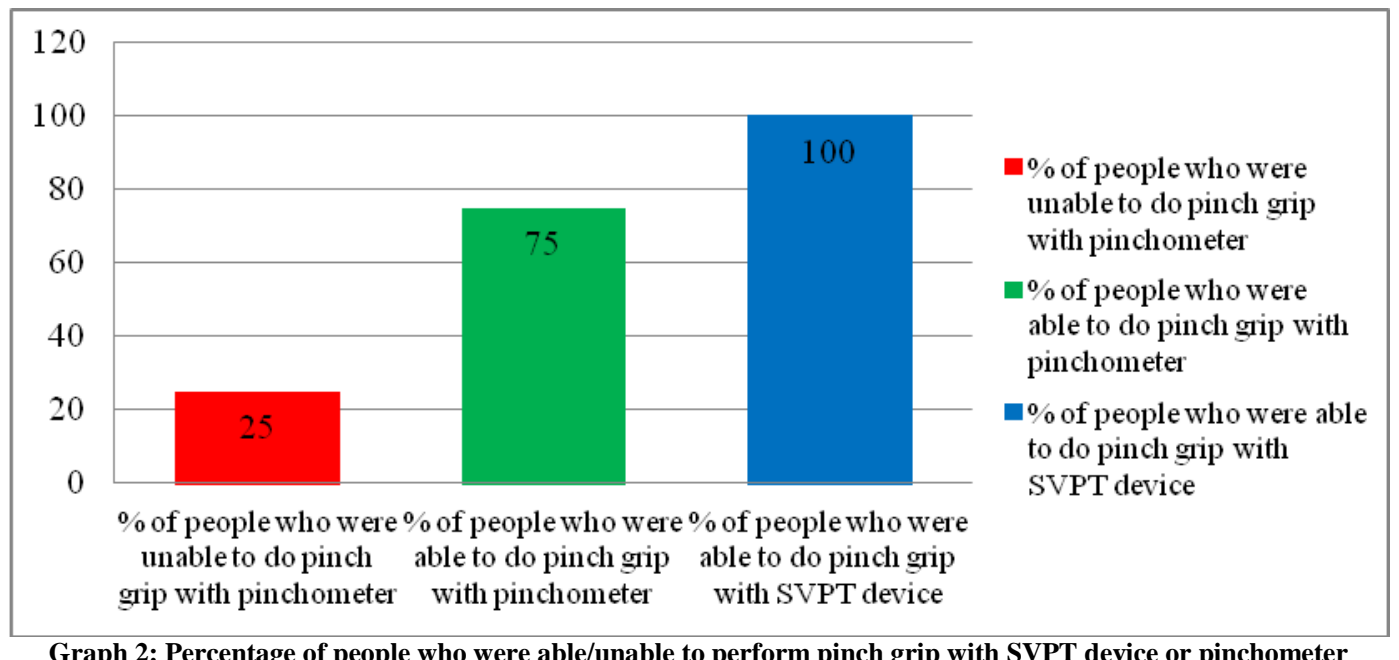

\section{DISCUSSION}

The aim of the study was to develop and validate an instrument (SVPT device) that can assess the pinch grip strength in neurological patients with the standard pinchometer device. The measurements of SVPT device were recorded on a Smartphone application.

The results of the present study shown that SVPT device provides lesser values than pinchometer because of its shape and design, and SVPT device is a valid tool to measure pinch grip strength in patients having neurological conditions as they were able to do pad to pad contact on pressure sensor of the device because of its more height as compared to pinchometer. The patients also required assistance to hold the pinchometer while measuring grip strength whereas; they were able to do pad to pad grip with SVPT device independently.

SVPT Device shows lesser values than pinchometer because it has more height than pinchometer and pinchometer has a surface congruent with the finger pads which makes it easier to press. But in some neurological patients it was seen that they were unable to do pad to pad contact on pinchometer. SVPT Device gives continuous values whereas, pinchometer gives discrete values.

Though kappa statistic shows poor strength of agreement between SVPT device and Pinchometer, the neurological patients were able to do pad to pad grip with SVPT device independently whereas it was difficult for them to do it with pinchometer. Strength of agreement between the two instruments may be because of the different length tension relationship of muscles used for pinch grip due to difference in pad to pad distance of both the instruments.

For future recommendations study can be done by upgrading the shape and design of the SVPT device. In addition to it further study can be done with equal number of patients in each neurological condition.

\section{CONCLUSION}

Development and validation of Smart Virtual Physical Therapist (SVPT) Device helps to assess the pinch grip by providing visual biofeedback using wireless connectivity as its measurements are recorded on Smartphone application. Parallax error occurs when the measurement on pinchometer is more or less than true reading because of eye being positioned at an angle to the measurement markings. But chances of parallax error reduce in SVPT Device in contrast to pinchometer.

Smart Virtual Physical Therapist device can't be replaceable with the standard baseline pinchometer to assess the grip strength. So modification in SVPT device can provide similar values to pinchometer. But it is a valid tool to measure pinch grip strength in neurological 
Mehta Krupa et.al. Development and validation of SVPT device for assessing pinch grip strength among neurological patients.

patients due to greater height of pressure sensor of SVPT device for pad to pad grip.

\section{Acknowledgement: None}

\section{Conflict of Interest: None}

\section{Source of Funding: None}

\section{Ethical Approval: Approved}

\section{REFERENCES}

1. Austin N. The Wrist and Hand complex. In Levangie P, Norkin C. Joint Structure and Function. 4th ed.: F A Davies company; 2005. p. 340.

2. Walankar P, Verma C, Mehta A. Study of hand grip strength in Indian population. Int $\mathbf{J}$ Health Sci Res. 2016;6:162-6.

3. Magee DJ. Forearm, Wrist and Hand. In 4th, editor. Orthopaedic Physical Assessment. Elsevier; 2006. p. 376.

4. Barut C, Demirel P. Influence of testing posture and elbow position on grip strength. Medical Journal of Islamic World Academy of Sciences. 2012 Jul;109(413):1-4.

5. Incel NA, Ceceli E, Durukan PB, Erdem HR, Yorgancioglu ZR. Grip strength: effect of hand dominance. Singapore medical journal. 2002 May 1;43(5):234-7.

6. Crosby CA, Wehbé MA. Hand strength: normative values. The Journal of hand surgery. 1994 Jul 1;19(4):665-70. doi: 10.1016/0363-5023(94)90280-1

7. Kuzala EA, Vargo MC. The relationship between elbow position and grip strength. American Journal of Occupational Therapy. 1992 Jun 1;46(6):509-12. doi: 10.5014/ajot.46.6.509.

8. Reed T, Fabsitz RR, Selby JV, Carmelli D. Genetic influences and grip strength norms in the NHLBI twin study males aged 59-69. Annals of human biology. 1991 Jan

\section{$1 ; 18(5): 425-32$. $10.1080 / 03014469100001722$}

doi:

9. Mathiowetz V, Kashman N, Volland G, Weber K, Dowe M, Rogers S. Grip and pinch strength: normative data for adults. Archives of physical medicine and rehabilitation. 1985 Feb 1;66(2):69-74.

10. Kaur M. Age-related changes in hand grip strength among rural and urban Haryanvi Jat females. Homo. 2009 Sep 1;60(5):441-50. doi: 10.1016/j.jchb.2009.06.002.

11. Koley S, Kaur N, Sandhu JS. A study on hand grip strength in female labourers of Jalandhar, Punjab, India. Journal of Life Sciences. 2009 Jul 1;1(1):57-62. doi: 10.1080/09751270.2009.11885135

12. Sorani DM, Rathod SR. Reference values of Grip strength by Hand Held Dynamometer in Gujarati Population. National Journal of Integrated Research in Medicine. 2019 Jan $1 ; 10(1)$

13. Fernández-de-las-Peñas C, Pérez-deHeredia-Torres M, Martínez-Piédrola R, de la Llave-Rincón AI, Cleland JA. Bilateral deficits in fine motor control and pinch grip force in patients with unilateral carpal tunnel syndrome. Experimental brain research. 2009 Mar 1;194(1):29-37. doi: 10.1007/s00221-008-1666-4.

14. Mathiowetz V, Vizenor L, Melander D. Comparison of baseline instruments to the Jamar dynamometer and the B\&L engineering pinch gauge. The Occupational Therapy Journal of Research. 2000 Jul;20(3):147-62.

doi; $10.1177 / 153944920002000301$

How to cite this article: Mehta K, Mair K, Mair $S$ et.al. Development and validation of SVPT device for assessing pinch grip strength among neurological patients. Int J Health Sci Res. 2021; 11(8):108-113. DOI: https://doi.org/10. 52403/ijhsr.20210816 